\title{
DEFORMAÇÃO DE ROCHAS GRANITÓIDES EM REGIME DÚCTIL: O EXEMPLO DO GNAISSE ESTRELA, REGIÃO DE CARAJÁS
}

\author{
CARLOS E.M. BARROS* \& ROBERTO DALL'AGNOL**
}

\begin{abstract}
DEFORMATION OF GRANITOID ROCKS UNDER DUCTILE CONDITIONS: THE EXAMPLE OF THE ESTRELA GNEISS, CARAJÁS REGION. The Estrela Gneiss is an Archaean gneiss-granitic body that outcrops to the east of the Serra dos Carajás. Detailed microscopic studies of these gneisses and deformed pegmatoid rocks revealed several microstructures in grains of quartz, feldspars and mafic minerals, indicating plastic flow during deformation. The microstructural features appear firstly in quartz, afterwards they are observed in K-feldspars and finally in plagioclase. The evolution of these microstructures follows the sequence: 1 . wavy extinction; 2 . kink bands; 3 . sub-grains; 4 . new grains; 5 . wavy extinction in new grains; and 6. cyclic recrystallization. During the stages 1 and 2 recovery mechanisms are more important, however, when dynamic recrystallization is present, mechanisms of sub-grain rotation and grain boundary migration start to act. The interaction of these processes account for a global plastic behavior and the rheological contrasts between quartz and feldspars become negligible. The ductile behavior of feldspars suggests that shear zones developed under temperatures higher than $500^{\circ} \mathrm{C}$.
\end{abstract}

Keywords: orthogneisses, ductile deformation, Estrela Gneiss, Archaean, Carajás.

RESUMO O Gnaisse Estrela aflora a leste da Serra dos Carajás e compreende um corpo batolítico granitognáissico de idade arqueana. $\mathrm{O}$ estudo microestrutural ótico destes gnaisses e de frações pegmatóides a eles associadas permitiu a caracterizacão de diversas feições microestruturais nos cristais de quartzo, feldspatos e nos minerais máficos. A evolução das microestruturas respeita a seguinte seqüência: 1. extinção ondulante; 2. kink bands; 3 . subgrãos; 4. novos grãos; 5 . extinção ondulante em novos grãos; 6 . Recristalizaçãocíclica.

$\mathrm{Na}$ transição dos termos relativamente menos deformados para as rochas miloníticas/ultramiloníticas, observase que a seqüência acima mencionada é observada mais prontamente nos cristais de quartzo, posteriormente nos feldspatos e, finalmente, nos cristais de anfibólios. Durante os estágios 1 e 2, atuaram mecanismos de recuperação, ao passo que, quando a recristalização dinâmica começa a atuar, tornam-se mais importantes os mecanismos de rotação de subgrãos e de migração de limites de grãos. A interação desses processos provoca o comportamento dúctil-global da rocha e as diferenças reológicas entre os vários minerais envolvidos passam a ser negligíveis. Tendo em vista o comportamento dúctil dos feldspatos, puderam ser estimadas temperaturas superiores a $500^{\circ} \mathrm{C}$ e pressões de $5 \pm 1$ kbar para o metamorfismo associado à instalação das zonas de cisalhamento dúctil pertencentes aos Sistemas Transcorrentes de Curionópolis.

Palavras-chave: ortognaisses, deformação dúctil, Gnaisse Estrela, Arqueano, Serra dos Carajás.

INTRODUÇÃO O Gnaisse Estrela situa-se a leste da Serra dos Carajás, próximo aos quilômetros 30 e 60 da Rodovia PA-275, que liga o Município de Marabá até a referida serra (Fig. 1). Esta unidade litoestrutural ocorre sob a forma de um corpo elíptico, alongado na direção E-W, aproximadamente.

Inicialmente, essas rochas foram designadas de Granito Estrela por Meireles et al. (1984). Anteriormente, Hirata et al. (1982) o correlacionaram aos granitos anorogênicos (Tipo Serra dos Carajás) do Proterozóico Inferior a Médio. A falta de estudos mais detalhados fez com que perdurasse esta correlação (DOCEGEO 1988). Dall'Agnol et al. (1986), ao observar algumas amostras dessas rochas, relatam diferenças petrográficas e estruturais entre as mesmas e os granitos anorogênicos. Com base nisso, descartaram tal correlação e sugeriram que o "Granito" Estrela teria sido deformado durante o Ciclo Transamazônico ou mesmo anteriormente.

Araújo et al. (1988) passaram a denominar tal unidade de Gnaisse Estrela, haja vista a presença de feições deformacionais neste corpo. Esses autores colocaram tais gnaisses em posição cronoestratigráfica inferior àquela aceita anteriormente. Naquela ocasião, interpretou-se que a evolução tectônica do Gnaisse Estrela deveria estar ligada ao desenvolvimento do Cinturão Itacaiúnas no final do Arqueano. Costa et al. (1990), em trabalho de maior detalhe nas áreas de ocorrência dos gnaisses em questão, conseguiram esbo- çar um arranjo estrutural resultante da instalação de zonas de cisalhamento oblíquo e direcional.

Com o quadro traçado acima, entendeu-se serem necessários estudos mais detalhados do Gnaisse Estrela e rochas encaixantes, a fim de aperfeiçoar seu conhecimento no que tange à geometria das estruturas maiores, as quais são discutidas em Barros (1991) e Barros et al. (1992).

Uma isócrona $\mathrm{Rb}-\mathrm{Sr}$ em rocha total revelou, para o Gnaisse Estrela, idade de $2.527 \pm 34 \mathrm{Ma}$ (Barros et al. 1992), a qual foi interpretada como possível idade do cisalhamento dúctil. Uma idade semelhante $(2.551 \pm 2 \mathrm{Ma})$ foi obtida por Machado et al. (1991) em formações ferríferas milonitizadas da região de Carajás, pelo método U-Pb em cristais de monazita. Tal idade foi relacionada à reativação do embasamento nessa região.

Mais ao sul, na região de Rio Maria, também são obtidas idades $\mathrm{Rb}-\mathrm{Sr}$ (rocha total) próximas das mencionadas acima, as quais não têm, aparentemente, significado geológico (Lafon et al. 1994), devendo ser interpretadas com cautela.

O presente trabalho pretende, por meio de estudo microestrutural ótico, descrever as diversas feições microestruturais relacionadas aos processos deformacionais, na tentativa de avaliar as condições reológicas sob as quais os protólitos do Gnaisse Estrela foram deformados, bem como determinar os mecanismos de deformação envolvidos.

\footnotetext{
* Bolsistas do CNPq, Brasil - Centre de Recherches Pétrographiques et Géochimiques, CRPG/CRNS, 15, Rue Notre-Dame dês Pauvres, BP 20, Vandoeuvre-lès-Nancy, 54500 France

** Departamento de Geoquímica e Petrologia, Universidade Federal do Pará
} 


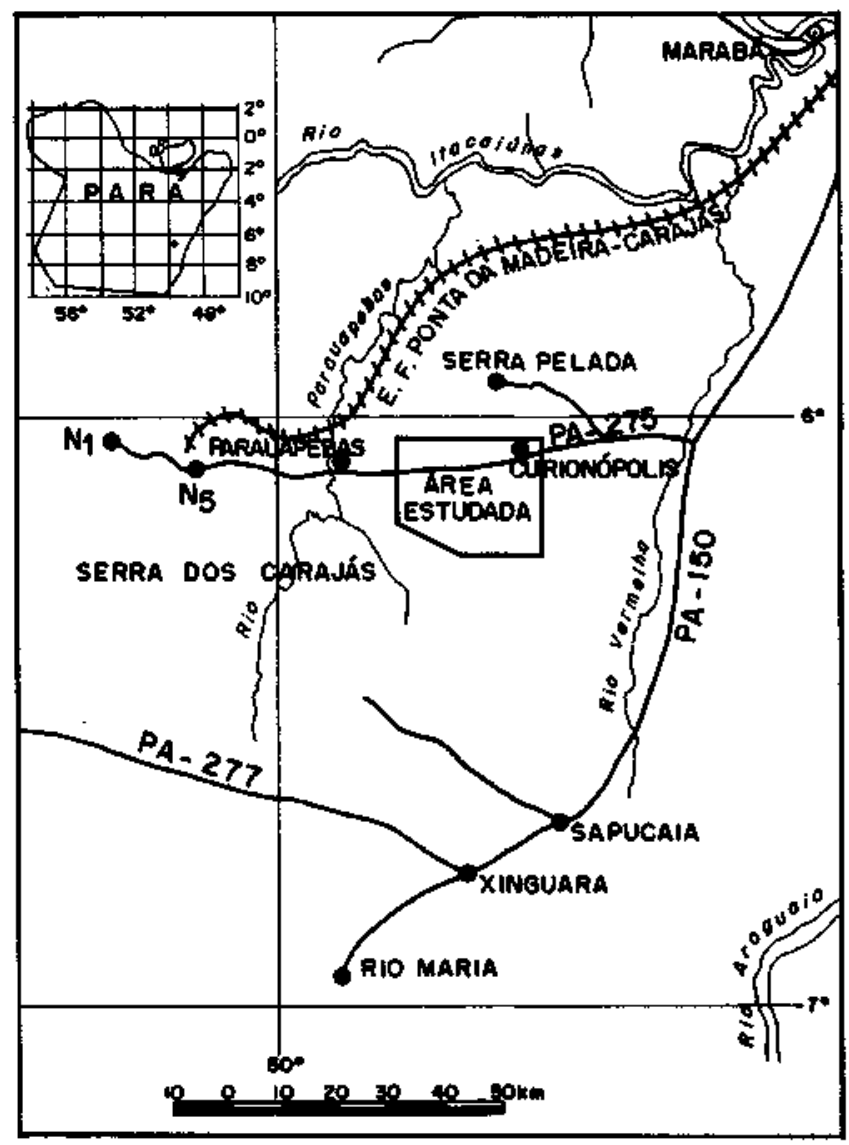

Figura I - Mapa de localização da área estudada Figure 1 - Location of the siudied area

GEOLOGIA DA ÁREA Na área estudada, o Gnaisse Estrela é limitado a norte e a sul por seqüências de rochas supracrustais metamorfisadas (Fig. 2).

$\mathrm{Na}$ porção norte, encontram-se principalmente anfibolitos, seguidos por grandes lentes de formações ferríferas bandadas e, subordinadamente, de cordierita quartzo-plagioclásio-biotita hornfels (Fig. 2). $\mathrm{O}$ arranjo estrutural dessas rochas encaixantes, a norte dos gnaisses estudados, parece ser bastante complexo, haja vista a grande variação da disposição espacial dos elementos planares e lineares. Adicionalmente, são descritas, nessas rochas, dobras de dimensões que variam de quilométricas, no caso das desenhadas pelas formações ferríferas, até centimétricas. E penetrativa uma foliação nos anfibolitos definida pela alternância de níveis de minerais máficos e níveis onde predominam cristais de plagioclásio. Ao microscópio, essas rochas revelam texturas granoblástica e nematoblásticas, indicando recristalização sob condições de equilíbrio (Bard 1990). Finalmente, observam-se bandas de cisalhamento discretas, de espessura decimétrica, cortando os anfibolitos.

Em meio aos gnaisses estudados, foram encontradas lentes métricas de anfibolitos e, subordinadamente, de cordierita quartzo-plagioclásio-biotita hornfels (Fig. 2), minôralógica e texturalmente semelhantes às encaixantes da parte norte da área.

As rochas encaixantes da parte sul são anfibolitos, granada-anfibólio-biotita gnaisses, granada-quartzo-plagioclásiobiotita gnaisses e quartzo-clorita-sericita xistos. Essas rochas são fortemente deformadas e apresentam foliação com atitude $\mathrm{EW} / 80 \mathrm{~N}$, cuja direção é concordante com o traço do contato entre essas e o Gnaisse Estrela (Fig. 2). A lineação de estiramento desses gnaisses encaixantes é caracterizada

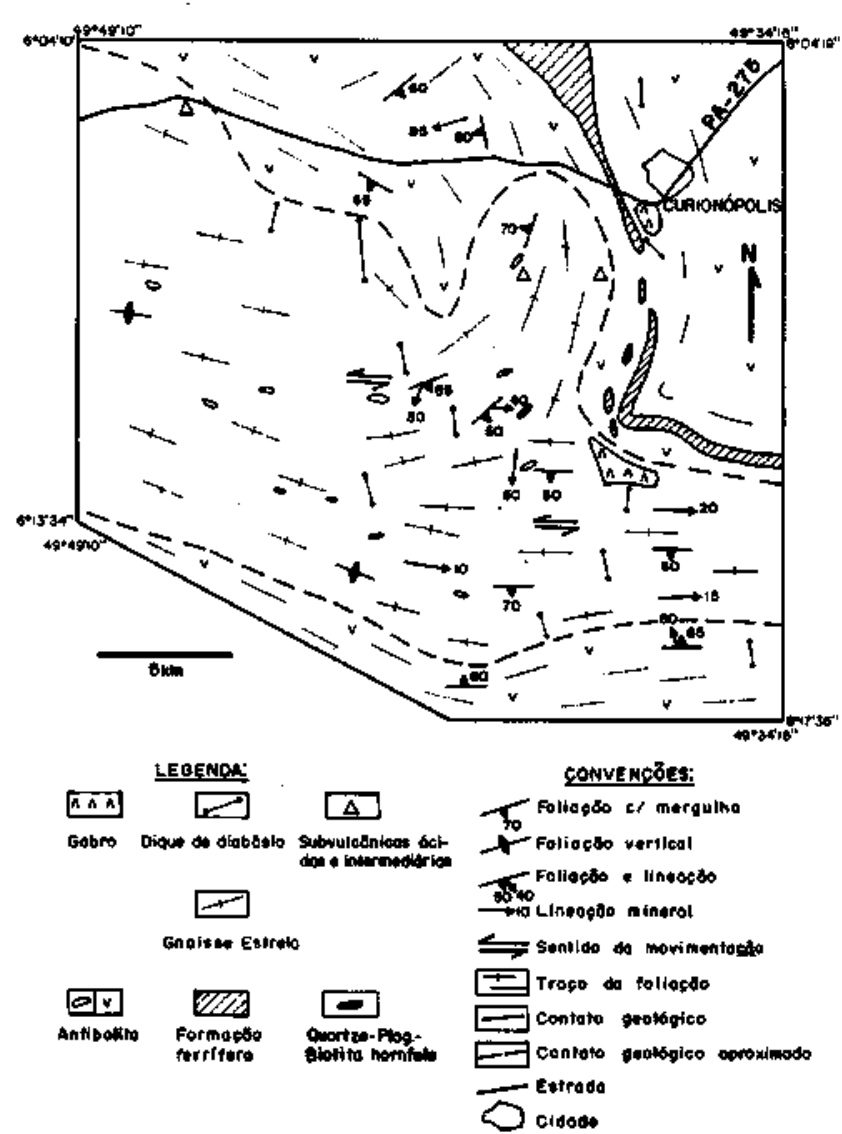

Figura 2 - Mapa geológico da porção estudada do Gnaisse Estrela

Figure 2 - Geologic map of the Estrela Gneiss studied area

por cristais de biotita orientados e dispostos nos planos da foliação. Ao microscópio, as rochas descritas nesse setor mostram fortes evidências de recristalização dinâmica, incluindo o crescimento sin-tectônico de porfiroblastos de granada, estiramento de cristais de anfibólio e recristalização acentuada, acompanhada de forte redução de granulação.

O Gnaisse Estrela compreende rochas granitóides fortemente deformadas durante a instalação de zonas de cisalhamento. A mais penetrativa encontra-se na parte sul do corpo, possui direção aproximada $\mathrm{E}-\mathrm{W}$ e movimentação transcorrente sinistrai. A norte do corpo, nota-se uma gradativa mudança no comportamento espacial da foliação, a qual passa a ganhar orientação NNE-SSW a N-S. Nesse setor, parecem ser mais importantes os esforços de natureza oblíqua.

A foliação é definida principalmente pela orientação dos minerais máficos que podem estar dispostos em níveis preferenciais melhor delimitados. Sobre o plano da foliação são observadas lineações minerais do tipo ribbon de elongação (cf. Mc Lelland, 1984), desenhadas por agregados de minerais máficos. Também são descritas estruturas de contração, representadas por dobras da foliação e dobras ptigmáticas, e por estruturas de extensão desenhadas por feições do tipo pinch-and-swell e boudins.

A nível microscópico, o Gnaisse Estrela caracteriza-se pela presença de uma foliação que varia de protomilonítica a milonítica, de acordo com a intensidade da deformação. Após a instalação de zonas de cisalhamento dúctil, a região foi submetida a esforços rúpteis que provocaram o fratura- 
mento e, eventualmente, falhamento de rejeito direcional decimétrico.

PETROGRAFIA Petrograficamente, o Gnaisse Estrela é constituído por rochas ortognáissicas de coloração cinzaclaro, granulação fina a média, e predominante composição monzogranítica. Subordinadamente, ocorrem variações sienograníticas e tonalíticas. Dentre os termos monzograníticos, distinguem-se: piroxênio-hornblenda monzogranitos gnáissicos, hornblenda monzogranitos gnáissicos, biotita-hornbenda monzogranitos gnáissicos, hornblendabiotita monzogranitos gnáissicos e biotita monzogranitos gnáissicos.

Cortando tais rochas, ocorrem veios quartzo-feldspáticos pegmatóides, os quais hospedam grandes cristais de anfibólio. Estas frações também foram deformadas ductilmente com diferentes intensidades. Ao que tudo indica, há cogeneticidade entre os gnaisses e essas rochas pegmatóides (Barros 1991, Barros \& Dall'Agnol em preparação).

EVOLUÇÃO MICROESTRUTURAL Para o estudo microestrutural do Gnaisse Estrela, foram selecionados dois grupos de amostras: monzogranitos gnaisses e frações pegmatóides deformadas.

Um aspecto que pode ser melhor compreendido, com base no estudo das microestruturas, diz respeito aos mecanismos de deformação durante o desenvolvimento das zonas de cisalhamento. Há, na bibliografia, vários trabalhos que abordam a questão da deformação de rochas granitóides e pegmatóides (Debat et al 1978, Berthé et al 1979, Wilson 1980, Vidal et al 1980, Vernon et al 1983, Burg et al 1984, Hackspacher \& Legrand 1989) ou que tratam da deformação de minerais individualmente, como os trabalhos relacionados à deformacão do quartzo (Bell \& Etheridge 1973, Tullis et al 1973, White 1977, 1979), plagioclásio (Vernon 1975, Brown et al 1980, Olsen \& Kohlstedt 1985, Olsen 1987, Ji \& Mainprice 1990) e feldspato potássico (Debat et al 1978, Vidal et al 1980, Tullis 1983).

Gnaisses monzograníticos ROCHAS PROTOMILONITICAS Nestas rochas, nota-se somente uma orientação preferencial incipiente dos minerais máficos (Prancha 1a).

- Quartzo: neste estágio, as feições deformacionais mais importantes são representadas por extincão ondulante forte com formação de bandas de deformação e subgrãos, não havendo marcante orientação preferencial dos cristais (Prancha Ib). Localmente, podem ser identificados neoblastos poligonais, cuja freqüência é maior à medida que a rocha apresenta-se mais intensamente deformada.

- Feldspato potássico: neste estágio, os cristais de feldspato potássico apresentam feições ligadas à deformação de modo muito tímido. Os cristais originais são médios (1-2 mm), dispõem-se com fraca orientação preferencial e exibem formas subédricas a anédricas. Alguns cristais podem ter pertitas (Prancha 1b), as quais se assemelham às pertitas em veio ou em mancha (cf. Ailing 1932), cuja origem supostamente está ligada à deformação (Vidal et al 1980). Outras feições muito locais são representadas por extinção ondulante, kink bands discretos e subgrãos. Os neoblastos são muito raros neste estágio e, quando presentes, ocorrem descontinuamente em bordas de porfiroclastos.

- Plagioclásio: não são verificadas importantes feições deformacionais nos cristais de plagioclásio, os quais parecem ser mais resistentes comparativamente ao feldspato potássico. Em alguns grãos, desenvolvem-se extinção ondulante e, raramente, kink bands.

- Biotita: este mineral ocorre como clastos, com orientação preferencial fraca a moderada. Localmente, apresentam kink bands.
- Hornblenda: neste estágio, há leve orientação dos cristais de hornblenda. Localmente, há incipiente recristalização das bordas deste mineral, nas quais se desenvolvem finos neoblastos. Estes neoblastos são dispostos segundo uma direção preferencial, subparalela aos porfiroclastos, contribuindo no desenvolvimento de uma foliação protomilonítica.

ROCHAS MILONÍTICAS Neste estágio, nota-se a presença de uma foliação melhor definida pela presença de níveis enriquecidos em minerais máficos alternados com níveis quartzo-feldspáticos.

- Quartzo: é mais comum a presença de bandas de deformação nos cristais originais e, gradativamente, nota-se o aumento da quantidade de neoblastos poligonais, cujos limites são melhor definidos e unidos por junções tríplices. Os neoblastos podem estar dispostos em agregados que, com o aumento da deformação, ganham orientação preferencial. Com o avanço da recristalização, a rocha passa a apresentar granulação mais fina e começa a ser melhor caracterizado o predomínio de uma matriz (Prancha $1 \mathrm{~d}$ ). - Feldspato potássico: os cristais de feldspato potássico originais apresentam orientação preferencial moderada a forte, assumem formas amendoadas ou arredondadas, podendo ser denominados porfiroclastos em ribbon e globulares, respectivamente (Ji et al 1988, Ji \& Mainprice 1990). Com relação ao estágio anterior, verifica-se aumento na quantidade de neoblastos, os quais se desenvolvem nas bordas dos porfiroclastos, desenhando texturas do tipo manto e núcleo (White et al 1980, White \& Mawer 1986).

- Plagioclásio: os porfiroclastos mostram-se orientados, podendo exibir extinção ondulante e kink bands. Os porfiroclastos globulares podem ser envolvidos por finos neoblastos de quartzo e feldspato potássico, dispostos assimetricamente, configurando sombras de pressão (Prancha 2a). A recristalização inicial das bordas de cristais de plagioclásio gera finos neoblastos, também desenhando feições do tipo manto e núcleo.

- Biotita: os cristais de biotita dispõem-se em finos níveis descontínuos e ondulados, fortemente orientados e constituídos por finos neoblastos lamelares. Alguns clastos com incipiente extinção ondulante e kink bands podem ser encontrados.

- Hornblenda: os cristais de hornblenda apresentam-se fortemente orientados e dispostos em caudas de finos grãos recristalizados. Há marcante redução da granulação com relação ao estágio anterior, em resposta à recristalização. Alguns clastos mostram feições ocelares assimétricas do tipo fish (cf. Lister \& Snoke 1984) (Prancha 2a). Neste estágio é notável a maior quantidade de simplectitos (albita ? + epídoto ?), que se formam pela corrosão dos cristais de anfibólio, quando em contato com plagioclásio ou feldspato potássico.

\section{ROCHAS ULTRAMILONÍTICAS}

A recristalização acentuada dos minerais em resposta à forte deformação causou diminuição global da granulação da rocha, a qual se constitui, neste estágio, em uma matriz milonítica/ ultramilonítica (Prancha lê).

- Quartzo: os cristais relictos são muito raros e, quando presentes, acham-se fortemente deformados e orientados, ou como ribbons. Neste estágio, a avançada recristalização faz com que predominem os neoblastos finos, que constituem uma matriz milonítica a ultramilonítica (Prancha $1 \mathrm{f}$ ). Os novos grãos dos ribbons são retangulares e orientados segundo a direção desses agregados, tềm granulação variável e seus limites são retos a levemente serrilhados. Os neoblastos gradativamente passam a mostrar evidências localizadas de deformação como extinção ondulante, bandas de deformação e subgrãos. Localmente, os neoblastos apre- 
sentam-se novamente recristalizados, gerando novos grãos ainda menores.

- Feldspato potássico: neste estágio, os porfiroclastos são mais raros, mostram forte orientação preferencial e pertitas tectônicas, extinção ondulante e kink bands localizados. Há aumento na quantidade de grãos recristalizados aos quais podem estar associadas mirmequitas (Prancha 2b), cuja origem possivelmente está ligada aos processos de substituição envolvendo mecanismos de dislocation glide $e$ dislocation climb (Hackspacher \& Legrand 1989, Simpson \& Wintsch 1989). Quando a recristalização é total, os neoblastos muito finos passam a contribuir na formação de uma matriz milonítica a ultramilonítica (Prancha $\mathrm{lf}$ ).

- Plagioclásio: os porfiroclastos, neste estágio, são pouco freqüentes e mostram extinção ondulante e kink bands moderados. Com a recristalização avançada, passam a predominar os neoblastos poligonais quase eqüidimensionais, que se unem por contatos tríplices e limites retos a levemente curvos. Evidências de deformação em neoblastos são localizadas e expressas por extinção ondulante. Há uma pequena diminuição no teor de anortita dos neoblastos $\left(\mathrm{An}_{10-8}\right) \mathrm{com}$ relação aos teores observados nos porfiroclastos $\left(\mathrm{An}_{18-14}\right)$.

- Hornblenda e biotita: a recristalização destes minerais é total, o que reflete também a formação de uma matriz homogênea de granulação fina (Prancha 10-

Rochas pegmatóides Estas rochas ocorrem em veios de espessuras decimétricas a métricas, que cortam os gnaisses monzograníticos. Em áreas onde a deformação não foi muito intensa, estes veios podem estar dispostos discordantemente à foliação das suas encaixantes monzograníticas; porém, em locais de maior deformação, estes veios se mostram paralelizados e foliados.

ROCHAS PEGMATÓIDES NÃO-FOLIADAS Neste estágio, as frações pegmatóides não exibem, em amostras de mão, evidências de deformação (Prancha 3a); entretanto, a análise microscópica revela que estas rochas experimentaram esforços consideráveis.

- Quartzo: não há orientação preferencial dos cristais de quartzo, os quais ocorrem de modo intersticial sob a forma de agregados de finos neoblastos (Prancha 3a). Inclusões de quartzo em cristais de feldspato potássico apresentam extinção ondulante, indicando que a deformação da rocha foi realmente importante (Bell \& Etheridge 1973).

- Feldspato potássico: os cristais de feldspato potássico mostram extinção ondulante moderada a forte (Prancha 3b) e pertita de origem provavelmente tectônica. Nesta fase, já ocorrem neoblastos finos em bordas de alguns porfiroblastos, sem, contudo, configurar texturas do tipo manto e núcleo. Estes neoblastos apresentam contatos retos a levemente curvos e formas poligonais (Prancha 4a).

- Plagioclásio: os cristais de plagioclásio se mostram relativamente pouco deformados, pois os mesmos são envolvidos por megacristais de anfibólio; entretanto, são verificadas algumas microtexturas como extinção ondulante, kink bands, e neoblastos localizados.

\section{ROCHAS FOLIADAS (ESTÁGIO PROTOMILOIMÍ-} TICO) As frações pegmatóides foliadas exibem foliação moderada a forte, desenhada pela orientação preferencial de hornblenda, a qual se dispõe em níveis preferenciais descontínuos e alternados por níveis quartzo-feldspáticos (Prancha 3c). As diferentes feições deformacionais a seguir descritas e a intensidade em que elas ocorrem permitem situar estas rochas dentro do estágio protomilonítico.

- Quartzo: este mineral ocorre como agregados orientados de neoblastos, os quais esboçam formas de ribbon. Os neoblastos são muito semelhantes aos descritos nos gnaisses monzograníticos.
- Feldspato potássico: há fraca orientação preferencial dos porfiroclastos e a textura em manto e núcleo é penetrativa (Prancha 3d). Os neoblastos possuem granulação fina, formas poligonais caracterizadas por limites retos, unidos por junções tríplices (Prancha 4a). Localmente, ocorrem porfiroclastos com kink bands e pertitas tectônicas (Prancha 4c).

- Plagioclásio: da mesma forma que o feldspato potássico, é observada uma melhor orientação preferencial dos porfiroclastos de plagioclásio, em cujas bordas também se desenvolvem neoblastos, configurando texturas em manto e núcleo. Em limites de kink bands, formam-se, por vezes, neoblastos poligonais (Prancha 4b).

- Hornblenda: a orientação dos cristais de hornblenda é marcante, tanto no que se refere aos cristais relictos quanto aos finos neoblastos. Estes desenvolvem-se nas bordas dos primeiros e constituem finos níveis descontínuos.

ROCHAS MUITO FOLIADAS (ESTÁGIO MILOIMÍTICO) Quando fortemente deformadas, as frações pegmatóides mostram-se paralelizadas, passando a exibir foliação conspícua, definida pela alternância de níveis quartzofeldspáticos e de níveis ricos em hornblenda. Ambos são constituídos predominantemente por grãos recristalizados, o que dá à rocha um aspecto semelhante ao de augen-gnaisse (Prancha 3e).

Neste estágio, a evolução microestrutural dos minerais é muito semelhante à observada nos gnaisses monzograníticos do estágio ultramilonítico, entretanto, em virtude da intensa deformação, começam a ocorrer evidências de inicial recristalização cíclica dos diferentes minerais. Este processo é traduzido pela presença de níveis de neoblastos de quartzo, feldspatos e de anfibólio, extremamente finos e em bandas alternadas com níveis de neoblastos relativamente maiores, não afetados pela recristalização cíclica, o que atesta o caráter heterogêneo da deformação (Prancha 3f)-

METAMORFISMO Com base na observação das várias microestruturas acima descritas, foi possível determinar as condições de metamorfismo e caracterizar, de modo preliminar, os mecanismos de deformação durante a instalação das zonas de cisalhamento dúctil. Vários autores (White et al. 1980,Tüllis 1983, Capais 1989, Ji \&Mainprice 1990 e outros), ao estudar a deformação de rochas granitóides, conseguiram estabelecer limites de temperatura acima dos quais os feldspatos passam a se comportar ductilmente. Nestas condições, são favorecidos os mecanismos de recuperação e recristalização dos minerais.

No caso do Gnaisse Estrela, os feldspatos apresentam diversas feições microestruturais, tais como extinção ondulante, kink bands, formação de neoblastos, que indica os mecanismos acima mencionados e que confirmam as condições de temperatura em torno de $500^{\circ} \mathrm{C}-550^{\circ} \mathrm{C}$. Temperaturas semelhantes podem ser estabelecidas quando se observam milonitos com hornblenda, nos quais este mineral encontra-se recristalizado, formando finas caudas de neoblastos.

No que tange às condições de pressão, embora seja difícil a determinação de um intervalo mais preciso, podem ser feitas estimativas a partir de diagramas que correlacionem temperatura e pressão (Turner 1968, Winkler 1974) ou, ainda, que considerem o comportamento reológico dos materiais (Scholz 1988). Segundo esse autor, os feldspatos assumem um comportamento dúctil em profundidades de 15 a $21 \mathrm{~km}$, sob pressões de $6 \pm 1 \mathrm{kbar}$.

DISCUSSÃO E CONCLUSÃO As diferentes microestruturas dos minerais que constituem os gnaisses estudados podem ser utilizadas na caracterização dos mecanismos responsáveis pela deformação dos protólitos do Gnaisse Estrela. 


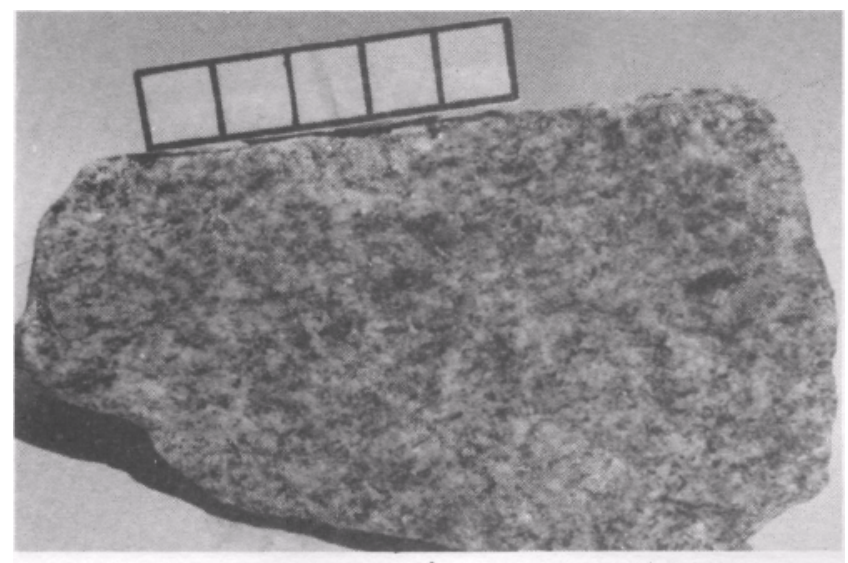

A
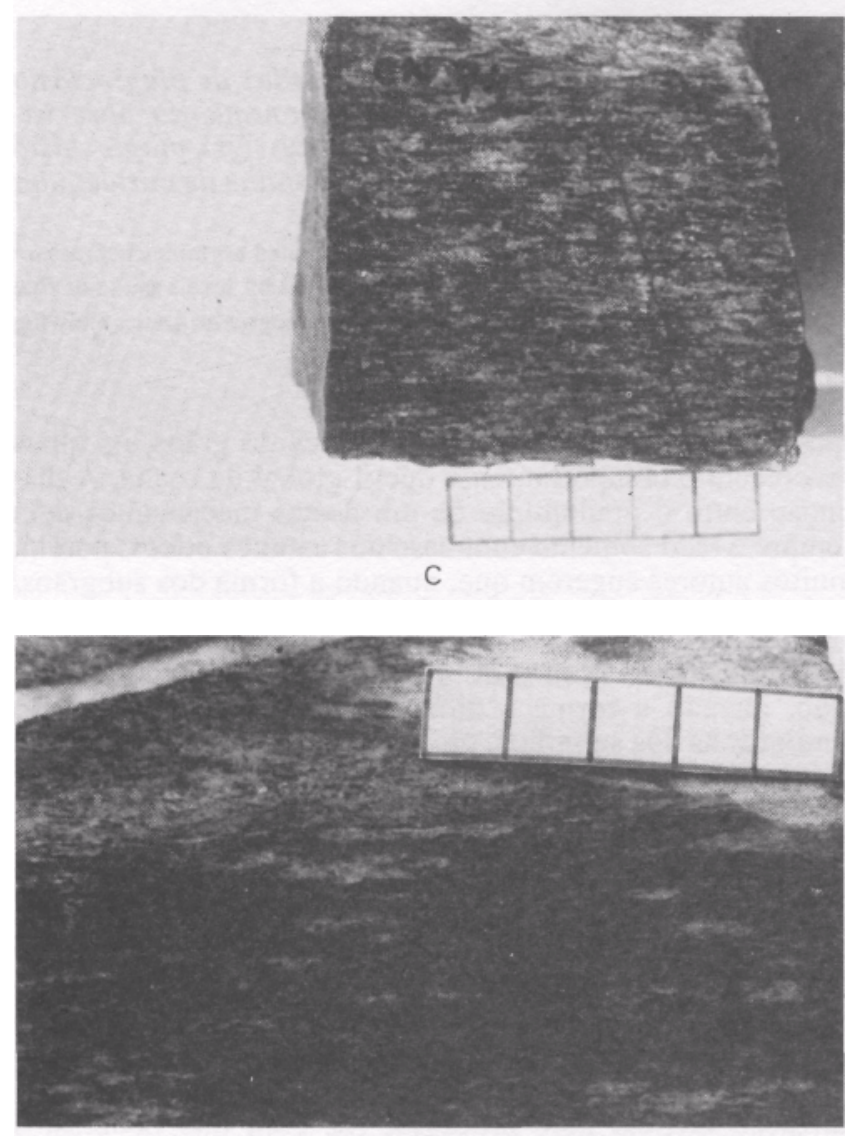

$\mathrm{E}$
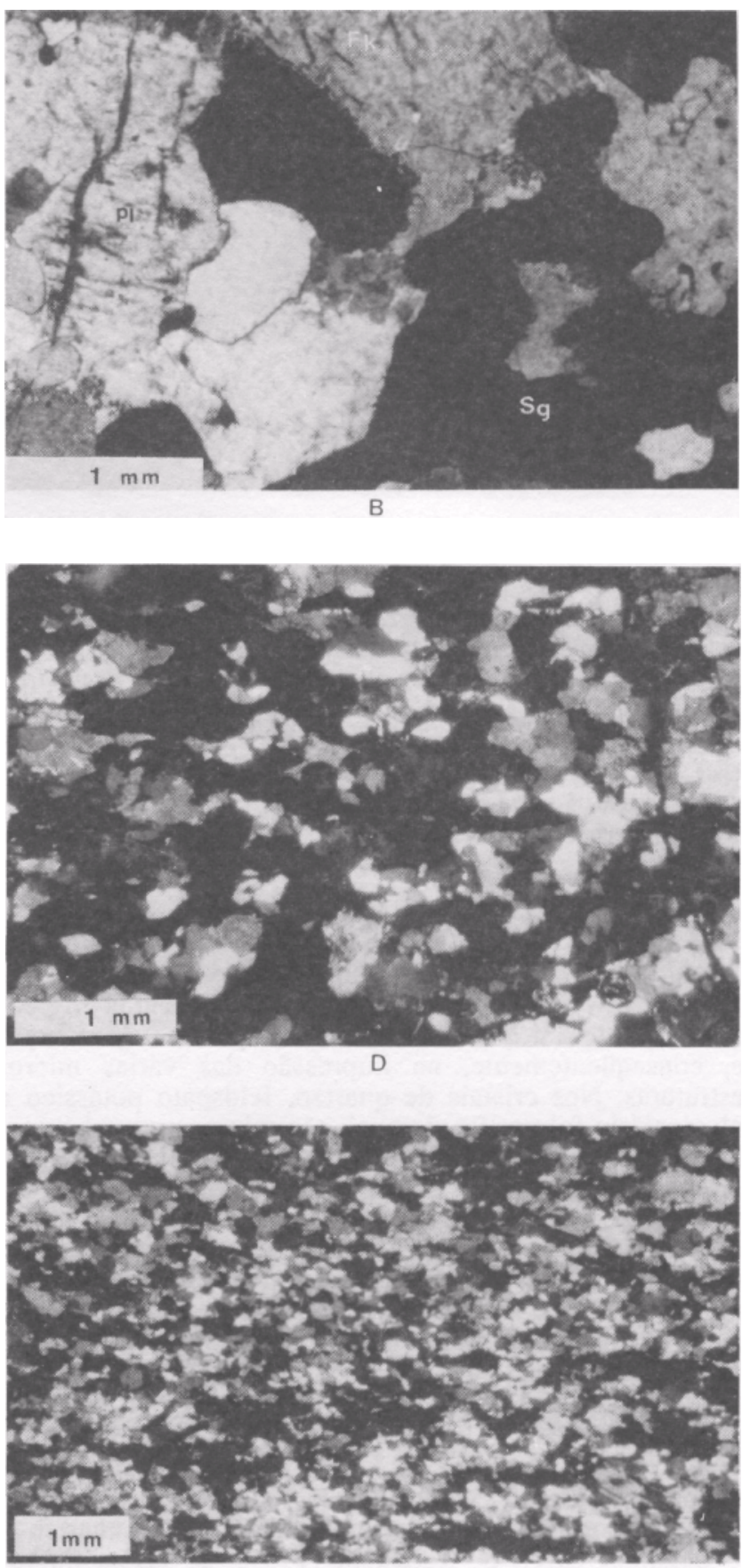

$\mathrm{F}$

Prancha 1 - a.Gnaisse protomilonítico mostrando foliação fraca, definida pela orientação preferencial dos minerais máficos (escala - $5 \mathrm{~cm}$ ); b. Fotomicrografia (nicóis $x$ ) da amostra da figura la. Neste estágio, nota-se somente a presença de extinção ondulante, bandas de deformação e subgrãos em quartzo; c. Gnaisse milonitico mostrando foliação melhor desenvolvida, definida pela alternância de níveis ricos em minerais máficos e níveis essencialmente quartzo-feldspáticos. Discordante da foliação, há fraturamento não-penetrativo (escala $=5 \mathrm{~cm}$ ); $d$. Fotomicrografla (nicóis $x$ ) da amostra da figura Ic. Percebe-se diminuição da granulação da rocha com relação ao estágio anterior, em virtude da recristalização inicial das bordas dos minerais; e. Granitóide fortemente deformado. Neste estágio, a avançada recristalização reduz drasticamente a granulação da rocha, a qual pode ser classificada como ultramilonito (escala $=5 \mathrm{~cm}$ ); $f$. Fotomicrografla (nicóis $x$ ) do gnaisse da figura anterior, na qual nota-se avançada recristalização dinâmica dos cristais tendendo para a formaçãodematrizmilonitica/ultramiloniticahomogênea

Plate 1 - a. Monzogranite in the protomylonitic stage showing weak foliation outlined by the preferential orientation of mafic minerals $(\mathrm{scale}=5 \mathrm{~cm})$; b. Photomicrograph (crossed nicols) of the sample from Plate la. In this stage the quartz grains show only undulatory extinction, kink-bands and subgrains; c. Monzogranite in the mylonitic stage showing a well developed foliation defined by the alternation of mafic-rich and quartz-feldspathic layers. A nonpenetrative fracturing cross-cuts the foliation (scale $=5 \mathrm{~cm}$ ); d. Photomicrograph (crossed nicols) of the sample from Plate Ic. Note the grain-size reduction due to the initial recrystallization of the grain margins; e. Strongly deformed granitoid. The advanced recrystallization drastically reduced the grain-size of the rock giving rise to an ultramylonite $(\mathrm{scale}=5 \mathrm{~cm}$ ); f. Photomicrograph (crossed nicols) of the gneiss from Plate le. Note the strong grain recrystallization, originating an homogeneous mylonitic/ultramylonitic matrix 

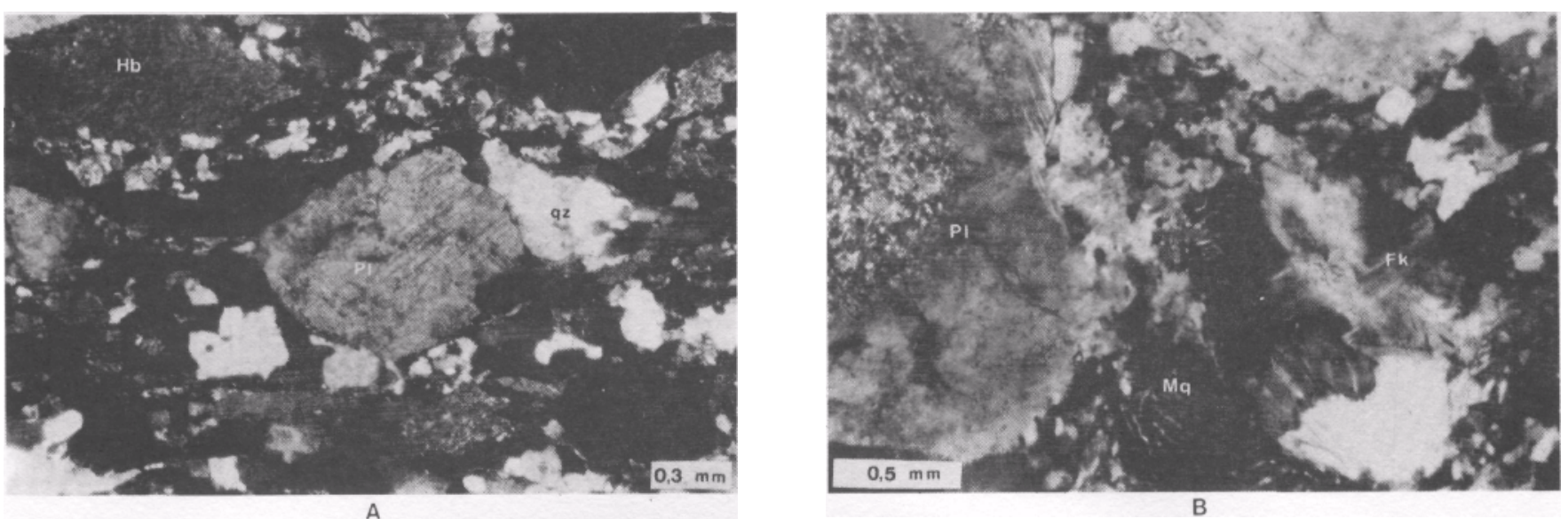

Prancha 2 - a. Fotomicrografia (nicóis $x$ ) de gnaisse monzo granitic o mostrando um porfiroclasto globular de plagioclásio envolvido por sombras depressão assimétricas, constituidas por neoblastos de quartzo. No canto superior esquerdo, observase porfiroclasto amendoado de hornblenda. Entre osporfiroclastos, há níveis de finos neoblastos de quartzo (Qz), plagioclásio (P1), feldspato potássico e hornblenda (Hb); $b$. Fotomicrografia (nicóis $x$ ) de gnaisse monzogranitico. Detalhe de mirmequita (Mq) sin-tectônica associada a neoblastos de feldspato potássico (Fk) e plagioclásio (P1)

Plate 2- a. Photomicrograph (crossed nicols) of monzogranite gneiss showing a globular porphyroclast of plagioclase with associated asymmetric pressure shadows made of quartz neoblasts. Note at the top-left an augen porphyroclast of hornblende. The porphyroclasts are surrounded by levels made of fine neoblasts of quartz (Qz), plagioclase (PI), potassic feldspar (Fk) and hornblende (Hb). b. Photomicrograph (crossed nicols) of monzogranite gneiss showing

a syntectonic myrmekite (Mq) associated to neoblasts of potassic feldspar (Fk) and plagioclase (PI)

A evolução microestrutural das rochas estudadas parece ter sido controlada pelos mesmos mecanismos nos diferentes minerais. Entretanto, observa-se que existe uma diferença no timing em que cada mineral responde aos esforços e, conseqüentemente, na impressão das várias microestruturas. Nos cristais de quartzo, feldspato potássico e plagioclásio foi verificada evolução microestrutural semelhante, a qual se caracteriza pelas seguintes etapas: 1. extinção ondulante; 2. bandas de deformação; 3. subgrãos; 4. novos grãos; 5. extinção ondulante de novos grãos; 6. recristalização cíclica. Entretanto, esta seqüência ocorre mais prontamente nos cristais de quartzo, ou seja, este mineral deforma-se sob condições menos árduas, sob as quais os cristais de feldspatos permanecem pouco afetados. Dentre os feldspatos, o plagioclásio tem comportamento mais resistente, relativamente ao feldspato potássico (Quadro 1) Debat et al. (1978), Etheridge \& Wilkie (1981, in Tullis, 1983) e Vermon et al. (1983) também fazem alusão à maior resistência dos cristais de plagioclásio com relação ao feldspato potássico e deste comparativamente ao quartzo.

Segundo Olsen \& Kolhstedt (1985), as várias microestruturas destes minerais têm o mesmo significado. Outro aspecto que deve ser abordado quando da deformação do plagioclásio diz respeito às implicacõos cristalográficas deste mineral, traduzidas pela forma e posicão do cristal original, relativamente aos esforcos aplicados ( $J i$ et al. 1988, Ji \& Mainprice 1990). A morfologia dos cristais de plagioclásio favorece a orientação dos planos (010) paralelamente à foliação. Entretanto, quando esses planos e a direcão de encurtamento fazem ângulos pequenos, os cristais apresentarão extinção ondulante, curvamento das macias ou, ainda, kinkbands.

Quanto aos mecanismos de deformação, durante os estágios 1 e 2, predominaram processos de recuperação no sentido de diminuir a quantidade de dislocations. Este processo é controlado por mecanismos de climb, os quais facilitam a movimentação não-conservativa de dislocations, produzindo subgrãos (White 1977).

Posteriormente, quando a recristalização predomina, os mecanismos de deformação esperados correspondem à rota- ção de subgrãos e migração de limites de grãos, os quais favorecem o comportamento dúctil global da rocha. A distinção entre o predomínio de um destes mecanismos nem sempre é fácil somente com base nos estudos óticos; porém, muitos autores sugerem que, quando a forma dos subgrãos/ novos grãos é poligonal e com limites retos a levemente curvos, devem ser mais importantes os mecanismos de deslizamento de limites de grãos (White 1977). Por outro lado, quando a forma e dimensões dos novos grãos são similares às dos subgrãos, predomina a rotação de subgrãos (White 1977, Vermon et al. 1983, Dell'Ângelo \& Tullis 1989). Alternativamente, podem estar presentes os dois mecanismos simultaneamente ou, ainda, podem atuar processos difusos (Tullis 1983, Jensey \& Starkey 1985).

No caso do Gnaisse Estrela, a igualdade da dimensão dos novos grãos e dos subgrãos é satisfeita, o que sugere a participação mais importante de rotação de subgrãos; entretanto, novos grãos retangulares evidenciam a contribuição de deslizamento de limites de grãos. Em condições de stress elevado, o Gnaisse Estrela parece ter experimentado recristalização cíclica. Este processo, fez com que neoblastos fossem novamente recristalizados e extremamente reduzidos em sua granulação, facilitando o fluxo plástico da rocha no decorrer da deformação.

A foliação do Gnaisse Estrela, embora mostre graus variados de intensidade - como resposta à heterogeneidade da deformação - é um elemento estrutural penetrativo na escala do corpo. Segundo Gapais (1989), o desenvolvimento de foliações penetrativas em corpos granitóides, com zonas ultramiloníticas, deve-se a softening. No Gnaisse Estrela, há concordância entre as temperaturas, deduzidas com base nas várias microestruturas e a penetratividade da foliação.

Com base nas condições reológicas discutidas acima, é pertinente a discussão do emprego do termo milonito. Segundo vários autores, milonito é rocha gerada em zonas de cisalhamento, na qual atuaram processos intracristalinos e que envolveram mecanismos de recuperação e recristalização, resultando em uma matriz de granulação fina que engloba, ou não, porfiroclastos, além de possuir orientação 
Quadro 1 - Quadro mostrando a evolução microestrutural do Gnaisse Estrela

Chart 1 - Summary of the microstructural evolution of the Estrela Gneiss

* Gnaisses monzograniticos

\begin{tabular}{|c|c|c|c|}
\hline & Protomilonito & Milonito & Ultramilonito \\
\hline Quartzo & $\begin{array}{l}\text { Extinção ondulante, bandas } \\
\text { de deformaçà, subgrăos e, } \\
\text { localmente neoblastos. Năo } \\
\text { há orientaçẫo preferencial. }\end{array}$ & $\begin{array}{l}\text { Extinção ondulante, bandas } \\
\text { de deformação, recristalizaçăo } \\
\text { intensa, reduçăo de tamanho } \\
\text { dos grãos e orientação } \\
\text { preferencial marcante dos } \\
\text { agregados de neoblastos }\end{array}$ & $\begin{array}{l}\text { Grāos relictos sāo raros, } \\
\text { predominam finos neoblastos } \\
\text { que compð̄em uma matriz } \\
\text { ultramilonitica. Forte } \\
\text { orientaçāo preferencial }\end{array}$ \\
\hline $\begin{array}{l}\text { Feldspato } \\
\text { Potássico }\end{array}$ & $\begin{array}{l}\text { Extinção ondulante muito } \\
\text { localizada, raros subgräos/ } \\
\text { novos grãos. }\end{array}$ & $\begin{array}{l}\text { Porfiroclastos orientados } \\
\text { com pertitas tectónicas, } \\
\text { tecristalização das bordas } \\
\text { dos clastos formando texturas } \\
\text { em manto e núcleo }\end{array}$ & $\begin{array}{l}\text { Porfiroclastos sāo raros, } \\
\text { quando presentes, eles mostram } \\
\text { extinçăa ondulante e "kink } \\
\text { bands". Mirmequita } \\
\text { sin-tectónica acompanha } \\
\text { finos ncoblastos }\end{array}$ \\
\hline Plagioclásio & $\begin{array}{l}\text { Extinçăa ondulante e, } \\
\text { subordinadamente. } \\
\text { "kink bands" }\end{array}$ & $\begin{array}{l}\text { Extinç̧̃o ondulante e "kink } \\
\text { bands" são mais comuns } \\
\text { Textura em manto núcleo } \\
\text { Orientaçăo preferencial } \\
\text { moderada }\end{array}$ & $\begin{array}{l}\text { Extinção ondulante, "kink } \\
\text { bands" nos raros porfiroclastos. } \\
\text { Recristalizaçăo intensa. } \\
\text { Marcante orientação } \\
\text { preferencial }\end{array}$ \\
\hline Hornblenda & Leve orientação preferencial & $\begin{array}{l}\text { Orientaçäo preferencial } \\
\text { marcante. Recristalização gera } \\
\text { finos neoblastos }\end{array}$ & $\begin{array}{l}\text { Recristalização quase total } \\
\text { gerando finos neoblastos }\end{array}$ \\
\hline Biotita & Fraca orientação preferencial & $\begin{array}{l}\text { Extinçāo ondulante "kink } \\
\text { bands", orientaçđ̃o preferencial } \\
\text { marcante }\end{array}$ & $\begin{array}{l}\text { Recristalização intensa e } \\
\text { orientaçăo preferencial } \\
\text { marcante }\end{array}$ \\
\hline
\end{tabular}

* Rochas pegmatóides

\begin{tabular}{|c|c|c|c|}
\hline & Protomilonito & Milonito & Ultramilonito \\
\hline Quartzo & $\begin{array}{l}\text { Extinção ondulante, subgrãos, } \\
\text { novos grăos. Não há orientaçăo } \\
\text { preferencial }\end{array}$ & $\begin{array}{l}\text { Orientação moderada dos } \\
\text { agregados de neoblastos. } \\
\text { Clastos apresentam extinção } \\
\text { ondulante e bandas de } \\
\text { deformação }\end{array}$ & $\begin{array}{l}\text { Orientação preferencial forte } \\
\text { dos agregados de neoblastos. } \\
\text { Recristalizaçãa cíclica }\end{array}$ \\
\hline $\begin{array}{l}\text { Feldspato } \\
\text { Potássico }\end{array}$ & $\begin{array}{l}\text { Extinçāo ondulante, pertitas e } \\
\text { mirmequitas tectônicas, "kink } \\
\text { bands" localizados. } \\
\text { Recristalizaçăo localizada }\end{array}$ & $\begin{array}{l}\text { Subgrãos e "kink bands" } \\
\text { localizados. Moderada } \\
\text { orientação preferencial. Novos } \\
\text { gräos e clastos formam textura } \\
\text { manto e núcleo }\end{array}$ & $\begin{array}{l}\text { Extinção ondulante forte, } \\
\text { orientação preferencial } \\
\text { marcante, recristalização } \\
\text { intensa }\end{array}$ \\
\hline Plagioclásio & $\begin{array}{l}\text { Extinçāo ondulante e "kink } \\
\text { bands" localizados. Incipiente } \\
\text { formação de neoblastos }\end{array}$ & $\begin{array}{l}\text { Clastos moderadamente } \\
\text { orientados, com extinção } \\
\text { ondulante e "kink bands" } \\
\text { localizados. Recristalizaçăo } \\
\text { de bordas de clastos gerando } \\
\text { textura em manto e núcleo }\end{array}$ & $\begin{array}{l}\text { Clastos moderadamente } \\
\text { orientados, extinção ondulante } \\
\text { e "kink bands" localizados. } \\
\text { Textura em manto e núcleo }\end{array}$ \\
\hline Homblenda & $\begin{array}{l}\text { Localmente há formação } \\
\text { de neoblastos }\end{array}$ & $\begin{array}{l}\text { Orientação moderada a forte. } \\
\text { Recristalização de bordas de } \\
\text { clastos }\end{array}$ & $\begin{array}{l}\text { Forte orientação preferencial, } \\
\text { reduçăo da granulação e } \\
\text { recristalizaçăo intensa }\end{array}$ \\
\hline
\end{tabular}



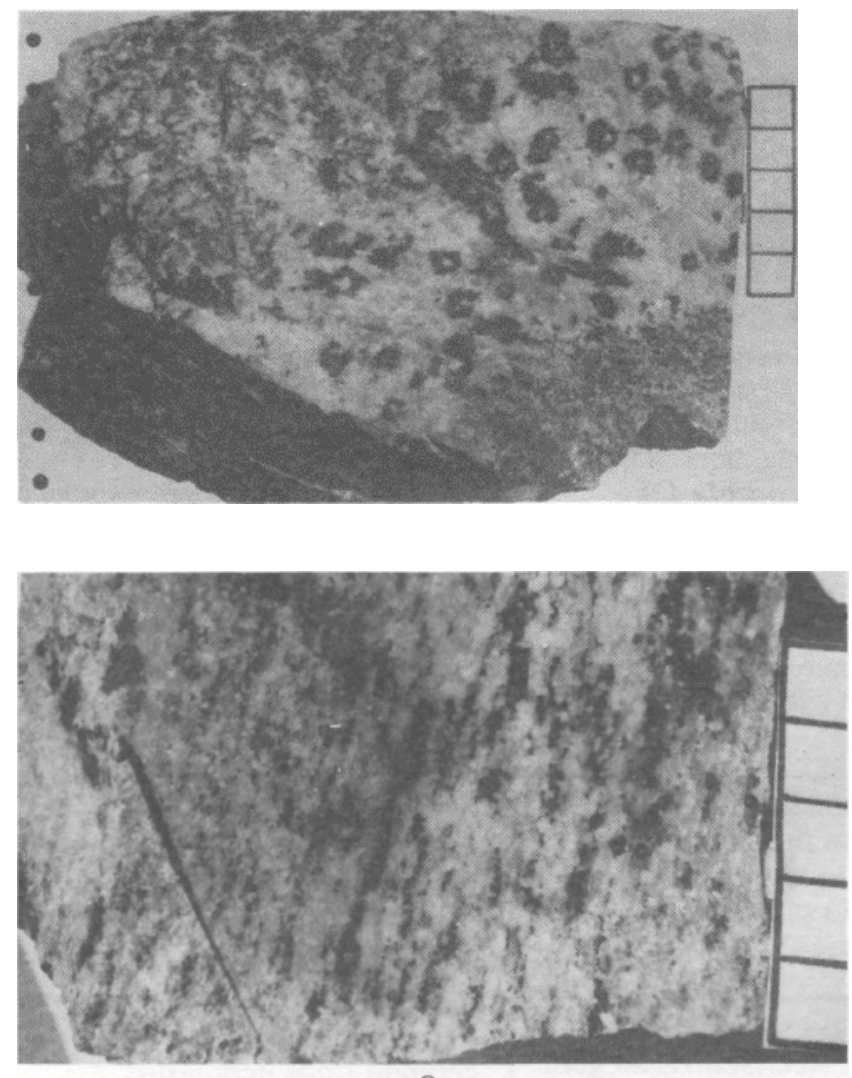

C

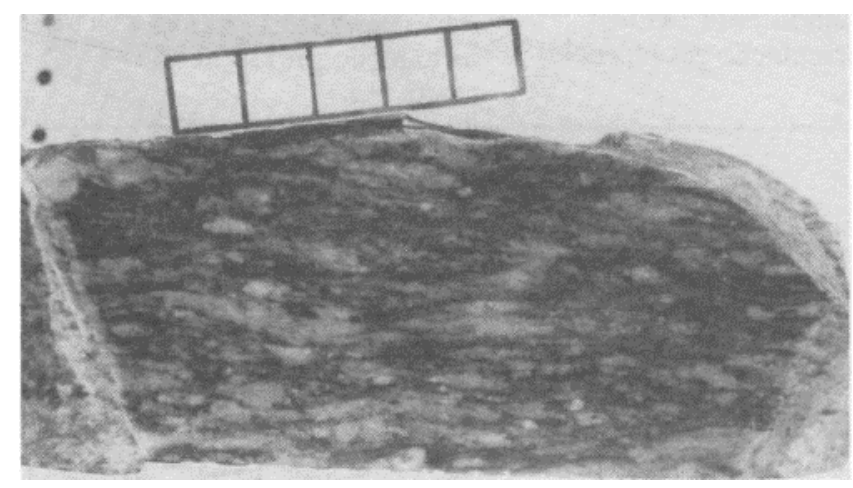

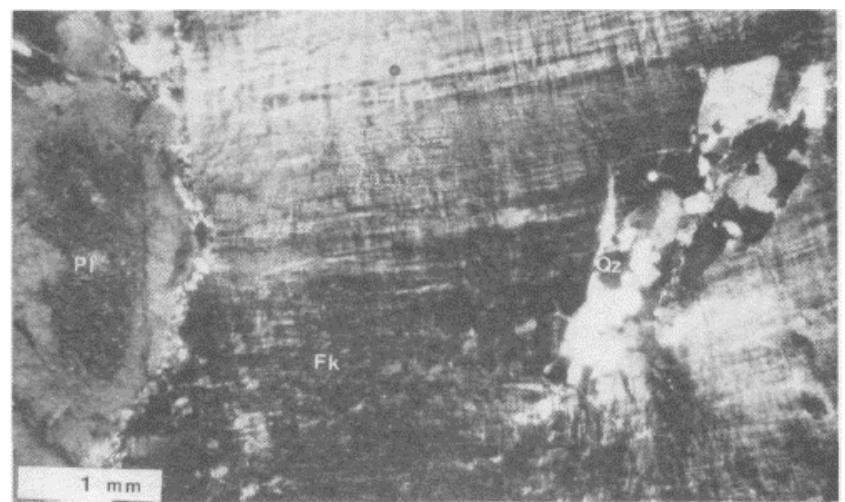

B
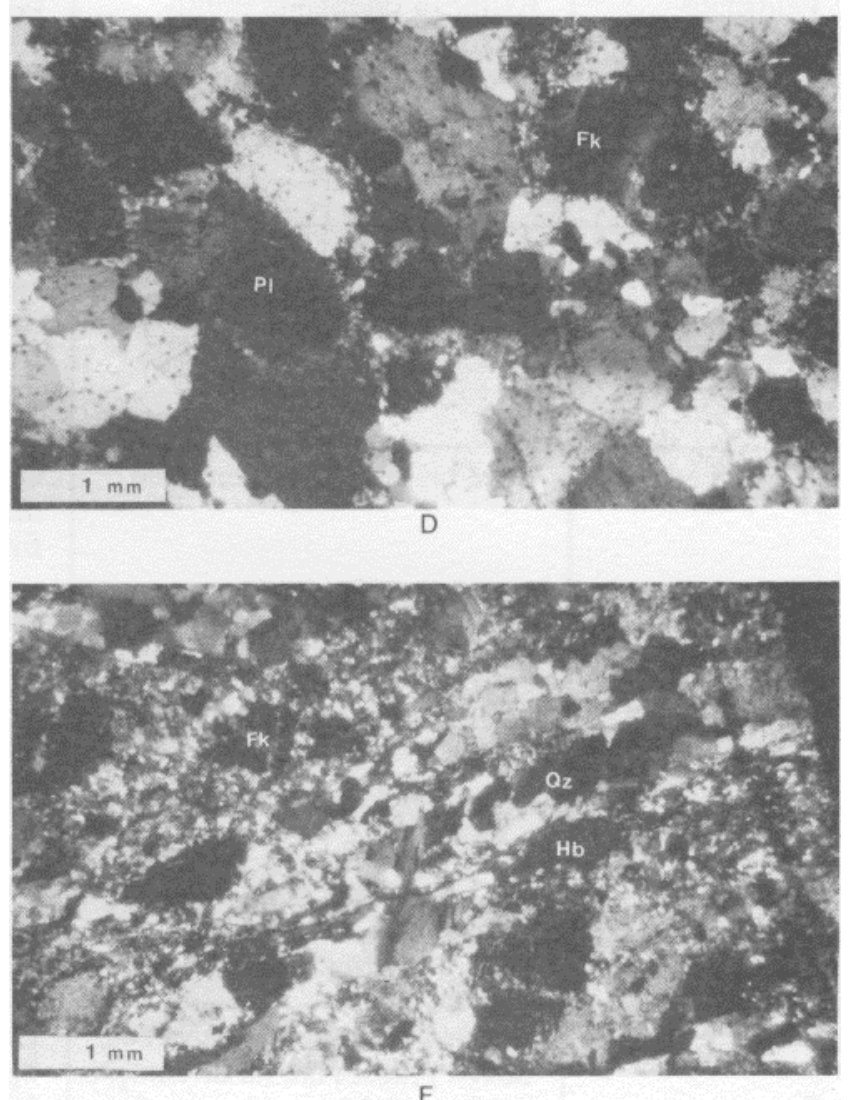

Prancha 3 - a. Fração de rocha pegmatóide não-foliada mostrando texturas possivelmente primárias, representadas por megacristais de anfibólios, enblobando agregados quartzo-feldspáticos, que acompanham o hábito prismático do anfibólio $($ escala $=5 \mathrm{~cm}) ; b$. Fotomicrografia (nicóis $x)$ da fração pegmatóide não-foliada, com evidências de deformação como a recristalização parcial das bordas defeldspatopotássico (Fk) e recristalização de quartzo (Qz) e plagioclásio (PI); c. Fração pegmatóide, com foliação moderadamente desenvolvida, definida pela alternância de níveis ricos em anfibólio e níveis quartzo-feldspáticos (escala $=5 \mathrm{~cm}) ; d$. Fotomicrografia (nicóis $x$ ) da fração pegmatóide foliada, mostrando uma melhor orientação preferencial dos porfiroclastos e a recristalização inicial das bordas dos mesmos, configurando a textura em manto e núcleo (PI: plagioclásio, Fk: feldspato potássico); e. Fração pegmatóide muito deformada, apresentando foliação fortemente desenvolvida e ondulante. Neste estágio, a rocha assume o aspecto de augen-gnaisse (escala = $5 \mathrm{~cm}) ; f$. Fotomicrografia (nicóis $x$ ) de fração pegmatóide muito deformada, na qual nota-se redução marcante da quantidade de porfiroclastos em virtude da avançada recristalização. Nota-se a formação de ribbons de quartzo (Qz), com subgrãos dispostos obliquamente ao seu alongamento, definindo uma foliação secundária (Fk: feldspato potássico, Hb: hornblenda) Plate 3 - a. Non-foliated pegmatoid rock showing primary textures represented by amphibole megacrysts that envelop quartzo feldspathic aggregates parallel to the c-axis of the host amphibole (scale $=5 \mathrm{~cm}$ ); b. Photomicrograph (crossed nicols) of a non-foliated pegmatoid rock showing evidence of deformation such as partial recrystallization of the borders of potassic feldspar (Fk) grains, and recrystallization of quartz (Qz) and plagioclase (PI); c. Moderately deformed pegmatoid rock showing a foliation defined by the alternation of amphibole-rich and quartz feldspathic layers ( $\mathrm{scale}=5 \mathrm{~cm}) ; \mathrm{d}$. Photomicrograph (crossed nicols) of a foliated pegmatoid rock showing a well developed preferential orientation of porphyroclasts and the initial recrystallization of their margins drawing a coreand-mantle textutes (PI: plagioclase; Fk: potassic feldspar); e. Highly strained pegmatoid rock showing a strong, anastomosed foliation. In this stage the rock resembles an augen gneiss (scale $5 \mathrm{~cm}$ ); f. Photomicrograph (crossed nicols) of a highly strained pegmatoid rock. The reduction of the number of porphyroclasts is a response to the advanced recrystallization. Note the presence of quartz $(\mathrm{Qz})$ ribbons with subgrains disposed obliquely to their lenglit, defining a secondary foliation (Fk: potassic feldspar; Hb: hornblende) 

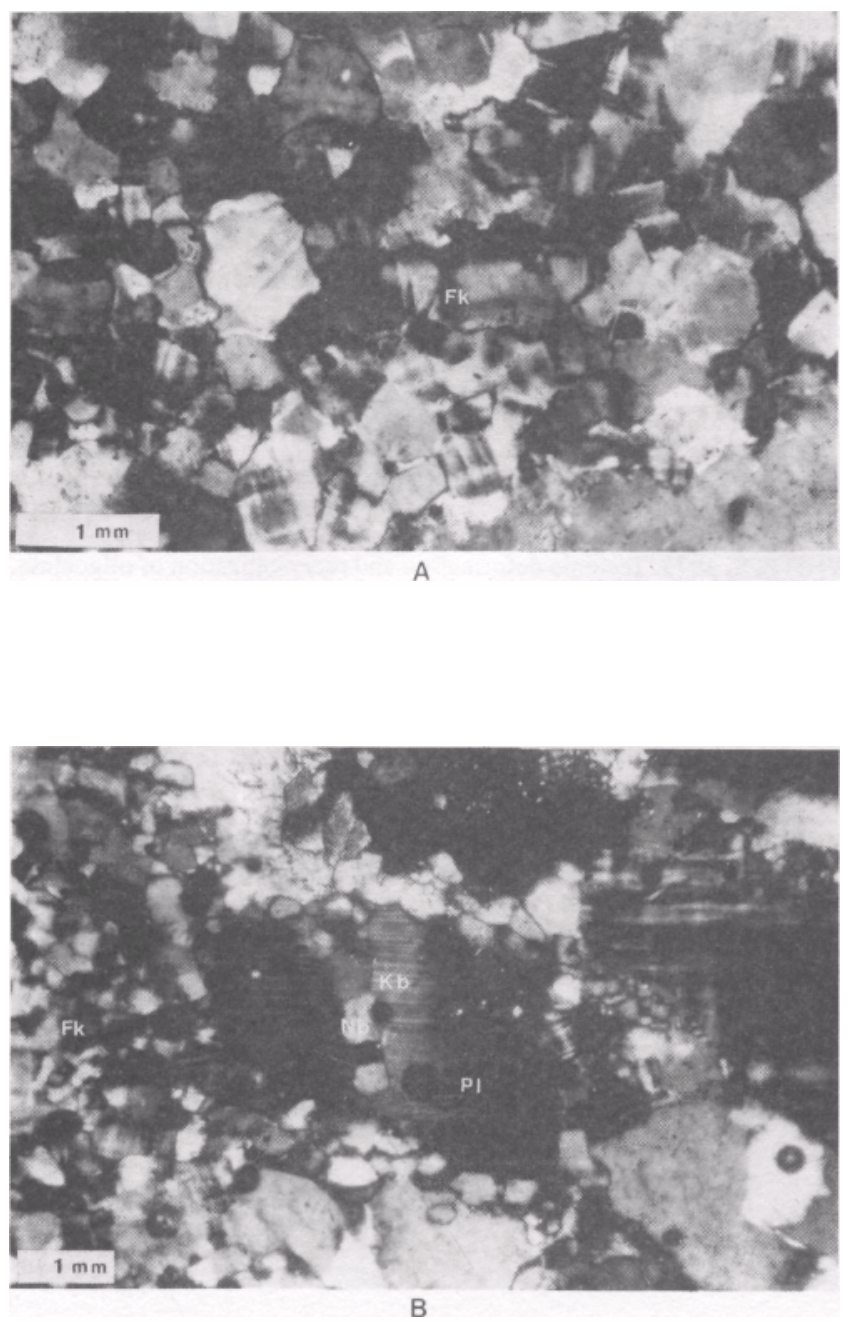

de forma e de fabric. Nesse sentido, o termo milonito pode ser utilizado para o Gnaisse Estrela, que foi submetido a graus mais intensos de recristalização.

Agradecimentos Agradecemos ao Conselho Nacional de Desenvolvimento Científico e Tecnológico (CNPq)

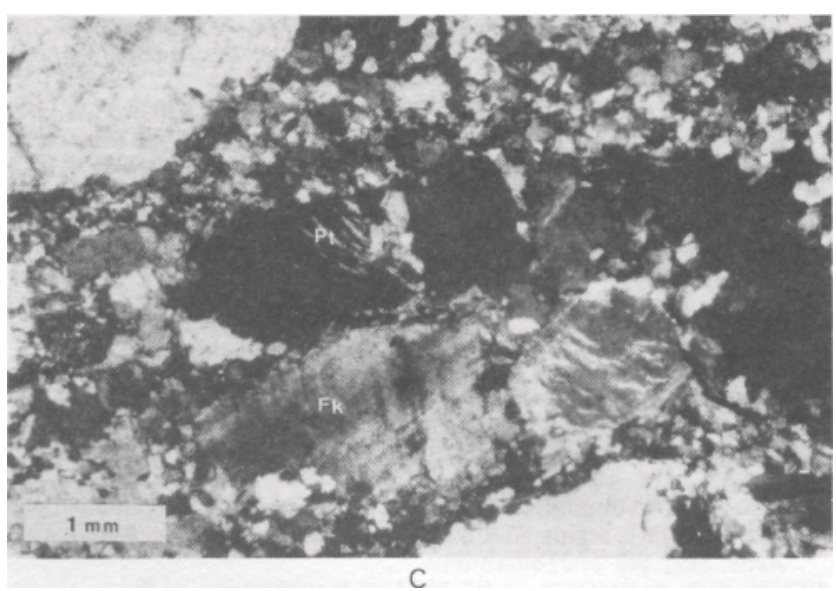

Prancha 4 - a. Fotomicrografia (nicóis $x$ ) de uma rocha pegmatóide não-foliada mostrando finos neoblastos poligonizados de feldspato polássico; $b$. Fotomicrografia (nicóis $x$ ) de fração pegmatóide foliada, na qual se nota a presença de neoblasios em limites de kink band $(\mathrm{Kb})$ em cristais de plagioclásio (PI) e bordejando-o (Fk: feldspato potássico); c. Fotomicrografia (nicóis x) de fração pegmatóide, mostrando porfiroclastos em ribbon de feldspato potássico (Fk), bordejados por neoblastos e exibindo pertita (Pt) em mancha

Plate 4 - a. Photomicrograph (crossed nicols) of a non-foliated pegmatoid rock showing fine polygonal neoblasts of potassic feldspar (Fk); b. Photomicrograph (crossed nicols) of a foliated pegmatoid rock showing neoblasts in kink bands $(\mathrm{Kb})$ boundaries in a plagioclase grain and neoblasts surrounding potassic feldspar; c. Photomicrograph (crossed nicols) of a pegmatoid rock showing ribbon porphyroclasts of potassic feldspar (Fk) surrounded by neoblasts. Note the presence of flame perthites $(\mathrm{Pt})$ in the potassic fedspar

pela concessão da bolsa de estudo (de mestrado), à Companhia Vale do Rio Doce (convênio CVRDUFPA-FADESP) e ao PADCT-FINEP (Projeto "Petrologia dos Granitos da Amazônia Oriental") pelo suporte financeiro, e ao colega Fernando Althoff pelas valiosas críticas e sugestões.

\section{REFERÊNCIAS BIBLIOGRÁFICAS}

ALONG, H.L. 1932. Perthites. Am. Mineral., 17(2):43-65.

ARAUUJO, O.J.B.; MAIA, R.G.N.; JOÃO, X.S.J. \& COSTA, J.B.S. 1988. A megaestruturação arqueana da Folha da Serra dos Carajás. In: CONGR. LAT. AMER. GEOL., 7. Belém, 1988. Anais... Belém, SBG. v. 1, p. 324-338.

BARD, J.P. 1985. Microtextitres dês Roches Magmatiques et Métamorphiques. Paris, Mason. $208 \mathrm{p}$

BARROS, C.E.M. 1991. Evolução Petrológica e Estrutural do Gnaisse Estrela, Citrionópolis, PA. Belém. 134 p. (Dissertação de Mestrado, CPGG-UFPA)

BARROS, C.E.M. \& DALL'AGNOL, R. Geochemistry of the Estrela Gneiss, Carajás Region, Brazil: an example of Archean A-type granitoid. Journal of South American Earth Sciences (submetido).

BARROS, C.E.M.; DALL'AGNOL, R.; LAFON, J.M.; TEIXEIRA, N.P. \& RIBEIRO, J.W. 1992. Geologia e Geocronologia Rb-Sr do Gnaisse Estrela, Curionópolis, PA. Boletim do Museu Paraense Emílio Goeldi, Série Ciências da Terra, 4:85-105.

BELL, T.H. \& ETHERIDGE, M.A. 1973. Microstructure of mylonites and their descriptive terminology. Lithos, 6:337-348.

BERTHE, D.; CHOUKROUNE, P. \& JEGOUZO, P. 1979. Orthogneiss, mylonites and non-coaxial deformation of granites: The example of the South Armorican Shear Zone. J. Struct. Geol, 1:31-42.
BROWN, W.L.; MACAUDIÈRE. J. \& OHNENSTETTER, M. 1980 Ductile shear zones in a meta-anorthosite from Harris, Scotland: textural and compositional changes in plagioclase. J. Struct. Geol. 2(1/2):281-287.

BURG, J.P.; BRUNEL, M.; GAPAIS, D.; CHEN, G.M. \& LIU, G.H. 1984 Deformation of leucogranites of the crystalline Main Central Sheet in southern Tibet (China). J. Struct. Geol., 6(5):535-542.

COSTA, J.B.S.; TEIXEIRA, N.P.; PINHEIRO, R.V.L. \& BERMERGUY, R.L. 1990. Os sistemas estruturais transcorrentes do Cinturão Itacaiúnas na região de Curinópolis, Leste do Estado do Pará. In: CONGR. BRÁS. GEOL.,35. Natal, 1990. Anais... Natal, SBG. 5:2345-2352.

DALL'AGNOL, R.; VIEIRA, E.A.P.; SÁ, C.A.S.; MEDEIROS, H.; GASTAL, M.C.P. \& TEIXEIRA, N.P. 1986. Estado atual do conhecimento sobre as rochas granitóides de porção sul da Amazônia Oriental. Rev. Brás. Geol., 16(1): 11-23.

DEBAT, P.; SOULA, J.C.; KUBIN, L. \& VIDAL, J.L. 1978. Optical studies of natural deformation microstructures in feldspars (gneiss and pegmatites from Occitania, southern France). Lithos, 11:133-145.

DELL'ANGELO, L.N. \& TULLIS, J. 1989. Fabric development in experimentally sheared quartzites. Tectonopltysics, 69:1-21.

GAPAIS, D. 1989. Shear structures within deformed granites: Mechanical and thermal indicators. Geology, 17:1144-1147. 
HACKSPACHER, P.C. \& LEGRAND, J.M. 1989. Microstructural and metamorphic evolution of the Portalegre shear zone, northern Brazil Rev. Bras. Ceoc., 19(1):63-75.

HIRATA, W.K.; RIGON, J.C.; KADEKARU, K.; CORDEIRO, A.A.C. \& MEIRELES, E.M. 1982. Geologia regional da província mineral de Carajás. In: SIMP. GEOL. AMAZONIA, 1. Belém, 1982. Atas... Belém, SBG. 1:100-110.

JENSEN, L.N. \& STARKEY, J. 1985. Plagioclase microfabrics in a ductile shear zone from Jotun Nappe, Norway. J. Struct. Geol., 7(5):527-539.

JI, S \& MAINPRICE, D. 1990. Recrystallization and fabric development in plagioclase. J. Geol., 98:65-79.

JI. S.; MAINPRICE, D. \& BOUDIER, F. 1988. Sense of shear in high temperature movement zones from asymmetry of plagioclase feldspars. J. Struct. Geol., 10(1):73-81.

LAFON, J.M.; RODRIGUES, E. \& DUARTE, K.D. 1994. Le Granite Mata Surrão: Un magmatisme monzogranitique contemporain dês associations tonalitiques - trondhjemitiques - granodioritiques archéenes de la region de Rio Maria (Amazonie oríentale, Brésil). C.R Acad. Sei., Ser. 2, 318:643-649.

LISTER, G.S. \& SNOKE, A.W. 1984. S-C mylonites. J. Struct. Geol., 6(6):617-638.

McLELLAND, J.M. 1984. The origin of ribbon lineation within the southern Adirondacks, USA.J. Struct. Geol.,6(1/2):147-157.

MEIRELES, E.M..; HIRATA, W.K.; AMARAL, A.F.; MEDEIROS F, C.A. \& GATO, V.C. 1984. Geologia das Folhas Carajás e Rio Verde, Província Mineral dos Carajás, Estado do Pará. In: CONGR. BRÁS. GEOL., 33. Rio de Janeiro, 1984. Anais... Rio de Janeiro, SBG. 5:2164-2174.

OLESEN, N.0.1987, Plagioclase fabrics development in a high-grade shear zone, Jotunheimen, Norway. Tectonophysics, 142:291-308.

OLSEN. T.S. \& KOHLSTEDT, D.L. 1985. Natural deformation and recrystallization of some intermediate plagioclase feldspars. Tectonophysics, 111:107-131.

RIO DOCE GEOLOGIA E MINERAÇÃO (DOCEGEO) 1988. Revisão litoestratigráfica da província mineral de Carajás. In: CONGR. BRÁS. GEOL., 35. Belém, 1988. Anexo aos Anais... Belém, SBG. p. 11-59.

SCHOLZ, C.H. 1988. The brittle-plastic transition and the depht of seismic faulting. Geol. Rundsch., 77(1):319-328.
SIMPSON, C. \&. WINTSCH, R.P. 1989. Evidence for deformation-induced K-feldspar replacement by myrmekite. J. Metamorph. Geol., 7:261-275

TULLIS, J. 1983. Deformation of feldspars. In: RIBBE, P.H. ed. Feldspar Mineralogy. Washington, Mineral. Soc. Am. p. 297-323. (Reviews in Mineralogy 2).

TULLIS, J.; CHRISTIE, J.M. \& GRIGGS, J.T. 1973. Microstructural and preferred orientation of experimentally deformed quartzites. Geol. Soc. Am. Bull., 84:297-314.

TURNER, F.J. 1968. Metamorphic Petrology (Mineral and Field Aspects). New York, Me Graw-Hill. 403 p.

VERNON, R.H. 1975. Deformation and recrystallization of plagioclase grain. Am. Mineral., 60:884-888.

VERNON, R.H.; WILLIAMS, V.A. \& D'ARCY, W.F. 1983. Grain-size reduction and foliation development in a deformed granitoid batholith. Tectonophysics, 92:123-145.

VIDAL, J.L.; KUBIN, L.; DEBAT, P. \& SOULA, J.L. 1980. Deformation and recrystallization of K-feldspar augen in orthogneiss from Montagne Noire, Occitania, Southern France. Lithos, 13:247-255.

WHITE, S. 1975. Tectonic deformation and recrystalization of oligoclase. Contrib. Mineral. Petrol.; 50:287-304.

WHITE, S. 1977. Geological significance of recovery and recrystallization processes in quartz. Tectonophysics, 39:143-170.

WHITE, S. 1979. Grain and sub-grain size variation across a mylonite zone. Contrib. Mineral Petrol., 70:183-202.

WHITE, S; BURROWS, S.E; CARRERAS, J; SHAW, N.D. HUMPHREYS, F.J. 1980. On mylonites in ductile shear zones. J. Struct. Geol. 2(1/2):175-187.

WHITE, J.C. \& MAWER, C.K. 1986. Extreme ductibility from a mylonite. Perry Sound. Canada. J. Struct. Geol., 2(1/2):203-209.

WINKLER, H.G.F. 1979. Petrogenesis of Metamorphic Rocks. 5 ed. New York, Springer-Verlag. 348 p.
MANUSCRITO A754

Recebido em 16 de fevereiro de 1993

Revisão do autor em 16 de junho de 1994

Revisão aceita em 15 de dezembro de 1995 